\title{
Gestational trophoblastic disease updated management
}

\author{
Mahmoud M Abdellatif, SabriM Mohamed, Ibrahim M A Hassanein , \\ Mohamed N Salem \\ Egypt, Sohaguniversity, Faculty of medicine
}

\section{Introduction}

Gestational trophoblastic
disease (GTD) is a group of
uncommon conditions associated with
abnormal pregnancy. Histologically, it
includes the benign partial and
complete hydatidiform mole, invasive
and metastatic mole, as well as the
malignant choriocarcinoma, placental
site trophoblastic tumor (PSTT), and
epithelioid trophoblastic tumor (ETT).
Molar pregnancies may develop
persistent elevated serum human
chorionic gonadotropin (hCG) levels
after evacuation (complete mole
15\%-20\%, partial mole $0.1 \%-5 \%$ [1]-
[3]), with a chance of progression to
choriocarcinoma that may require
treatment. Together with the malignant
forms of GTD these are grouped under
gestational trophoblastic neoplasia
(GTN).

\section{Epidemiology}

Molar pregnancy is more common in some parts of Asia, with reported incidence rates as high as 2 per 1000 pregnancies[4],[5] compared with Europe and North American where the incidence is usually reported to be less than 1 per 1000 pregnancies [6],[7]. However, the incidence of molar pregnancy seems to be decreasing in Asian countries, possibly related to improvements in the economy and diet as well as a decrease in birth rates [4].

The incidence of choriocarcinoma is difficult to estimate because of its rarity and trouble in clinically distinguishing postmolarchoriocarcinoma from invasive mole owing to lack of histologic biopsy material. Although choriocarcinoma has been reported to affect approximately 1 in 40000 to 9 in 40000 pregnancies [3], the incidence rates have been declining. PSTT and ETT are rarer than choriocarcinoma.

\section{Genetics and pathology}

3.1-Molar pregnancy:

Histologically, complete mole has florid cistern formation, trophoblastic proliferation, and absence of fetal parts. In contrast, such histological features are less

marked in partial mole and fetal parts are present, such as fetal cells [8]. Hydropic spontaneous abortion may mimic the appearance of partial mole.

Cytogenetics can help to differentiate complete mole from partial mole and hydropic spontaneous abortion. Typically, complete mole is diploid and has 46,XX chromosomes with both $\mathrm{Xs}$ from paternal origin whereas partial mole is triploid with maternal and paternal genetic origin. Hydropic spontaneous abortion normally has $46, \mathrm{XX}$ or XY from both parents. Immunohistochemical staining of p57Kip2, which is an imprinted gene, can help to show the presence of maternal genes and enable complete mole to be excluded [8], [9].

Rarely, invasive and metastatic moles can be diagnosed by removal of the uterus or a metastatic lesion.

3.2- Choriocarcinoma :

Choriocarcinoma is a malignant tumor with absence of chorionic villi, abnormal syncytiotrophoblast and 
cytotrophoblast, necrosis, and hemorrhage. It may invade the uterus and surrounding organs and it is common to have distant spread, particularly to the lung, but it may also involve the liver, spleen, kidneys, bowels, and brain [8].

3.3-Placental site trophoblastic tumor :

PSTT arises from the mononuclear intermediate trophoblast on the maternal side of the placental bed invading the myometrium. It has variable size and appearance, may be tan or yellowish with foci of necrosis, and on average is about $5 \mathrm{~cm}$ in size. Tumor cells have irregular nuclear membranes, hyperchromatic nuclei, and dense eosinophilic to amphophilic cytoplasm. Chorionic villi are absent. Tumor cells are strongly and extensively reactive to human placental lactogen (hPL) but only focally reactive to hCG. It has to be differentiated from the benign exaggerated placental site reaction where the Ki67 index is lower [8].

3.4- Epithelioid trophoblastic tumor :

ETT is a lesion of
chorionic-type intermediate trophoblast. It usually appears as a discrete, hemorrhagic, solid, and cystic lesion.

It may be found in the fundus, lower uterine segment, or endocervix, or even the broad ligament. Histologically, islands of intermediate trophoblastic cells are surrounded by extensive necrosis and associated with a hyaline-like matrix. The tumor is focally immunoreactive to hPL, hCG, cytokeratin, and inhibin-alpha. It can be differentiated from PSTT by positive p63 immunostaining. ETT may coexist with choriocarcinoma or
PSTT[10]-[12]. Emerging data indicate that atypical placental site nodules (APSN) can co-exist and/or preceded ETT and PSTT, suggesting that at least APSN cannot be regarded as benign [13].

\section{Clinical} investigation, and diagnosis

\section{1-Molar pregnancy :}

The most common presentation of a hydatidiform mole is abnormal vaginal bleeding in pregnancy. With the advent of ultrasound assessment of early pregnancy complications, molar pregnancy is usually diagnosed during the first trimester. Hence, the previous classical presentations of hyperemesis gravidarum, hyperthyroidism, pre-eclampsia, pulmonary trophoblastic embolization, and uterine size larger than dates are rarely seen nowadays.

The typical snow storm appearance of complete mole may not be seen in early first trimester complete mole. Absence of fetal parts, cystic appearance of the placenta, and deformed gestational sac may indicate early molar pregnancy. Hence, some molar pregnancies are only diagnosed on histological examination after dilation and curettage for a spontaneous abortion.

4.2- Gestational trophoblastic neoplasia :

Postmolar GTN is usually diagnosed by hCG surveillance. Patients are generally asymptomatic. At the 2000 FIGO Gynecology Oncology Committee meeting the definition of postmolar GTN based on hCG-level changes, histology, and specific investigations was agreed upon $(1,1)$ [14]. 
- When the plateau of hCG lasts for four measurements over a period of 3 weeks or longer; that is, days $1,7,14,21$.

- When there is a rise in hCG for three consecutive weekly measurements over at least a period of 2 weeks or more; days $1,7,14$.

- When the hCG level remains elevated for 6 months or more.

- If there is a histologic diagnosis of choriocarcinoma.

a Abbreviation: hCG, human chorionic gonadotropin.

Box 1- FIGO criteria for diagnosis of postmolar gestational trophoblastic neoplasia :

- Chest X-ray is appropriate to diagnose lung metastases and it is chest X-ray that is used for counting the number of lung metastases to evaluate the risk score. Lung CT may be used.

- Liver metastases may be diagnosed by ultrasound or CT scanning.

- Brain metastases may be diagnosed by MRI or CT scanning.

Box 2- Tools for investigation of gestational trophoblastic neoplasia:

\section{3- Human chorionic gonadotropin monitoring :}

For monitoring of GTN, an hCG assay that can detect all forms of hCG, such as beta-hCG, core hCG, C-terminal hCG, nicked-free beta, beta core, and preferably the hyperglycosylated forms, should be used; these are different from those used for a routine pregnancy test. A persistent low hCG level should be followed up, after exclusion of false positives due to heterophile antibodies, as some may progress to GTN with rising hCGlevel[15], [16].

4.4- Gestational trophoblastic neoplasia after non-molar pregnancy :

As only about $50 \%$ of GTN follows molar pregnancy, the rest can occur after a spontaneous abortion, ectopic pregnancy, or a term pregnancy where no hCG monitoring would be recommended. Therefore, clinical presentations vary from abnormal vaginal bleeding; bleeding from metastatic sites in the abdomen, lung, or brain; pulmonary symptoms; and neurological signs from spine or brain metastasis [3]. GTN should be considered in the differential diagnosis of patients with unusual presentations and serum hCG should be performed as part of the workup of such patients.

\section{Treatment}

\section{1- Molar pregnancy:}

Suction evacuation of molar pregnancy should be carried out by an experienced gynecologist, especially if the uterus is larger than 16 weeks gravid size and ideally under ultrasound guidance. The risk of heavy bleeding can be reduced with use of oxytocics given after dilation and the onset of suction curettage. If there is no persistent bleeding, second evacuation is usually not needed

Hysterectomy is rarely indicated unless there is a co-existing indication.

Follow-up with hCG monitoring is essential for early diagnosis of postmolar GTN. Recent data show that GTN rarely occurs after the hCG has spontaneously returned to normal and hence contraception for only 6 months rather than 1 year is now recommended [3], [17]. Termination of pregnancy is not indicated if accidental pregnancy occurs during surveillance after the hCG level has returned to normal. Also, data now show that it is safe to recommend oral contraceptives[18].

The risk of recurrence is low $(0.6 \%-2 \%)$ after one molar pregnancy, although much increased after consecutive molar pregnancies [19]-[21]. Mutations in NLRP7 and KHDC3L have been reported in women with recurrent molar pregnancy[22]-[24]. 


\section{2- Co-existing normal pregnancy with mole :}

Molar pregnancy rarely co-exists with a normal pregnancy. The diagnosis is usually made on ultrasound. Although there is a high risk of spontaneous abortion, about $40 \%$ result in live births without significantly increasing the risk of GTN [25]. Hence, in the absence of complications and normal genetic and ultrasound findings, pregnancy can be allowed to proceed.

\section{3- Gestational trophoblastic neoplasia:}

Treatment of GTN is generally by chemotherapy. The best regimen to use depends on stage and classification. In the 2000 FIGO staging and classification (Tables 1 and 2), a risk score of 6 and below is classified as low risk and above 6 is considered high risk.

\begin{tabular}{|c|l|}
\hline FIGO Stage & \multicolumn{1}{c|}{ Description } \\
\hline I & Gestational trophoblastic tumors strictly confined to the uterine corpus \\
\hline II & $\begin{array}{l}\text { Gestational trophoblastic tumors extending to the adnexae or to the vagina, but } \\
\text { limited to the genital structures }\end{array}$ \\
\hline III & $\begin{array}{l}\text { Gestational trophoblastic tumors extending to the lungs, with or without genital } \\
\text { tract involvement }\end{array}$ \\
\hline IV & All other metastatic sites \\
\hline
\end{tabular}

Table 1. FIGO staging and classification for gestational trophoblastic neoplasia :

\begin{tabular}{|l|l|l|l|l|}
\hline FIGO/WHO risk factor scoring with FIGO staging & $\mathbf{0}$ & $\mathbf{1}$ & $\mathbf{2}$ & 4 \\
\hline Age & $<40$ & $>40$ & - & - \\
\hline Antecedent pregnancy & Mole & Abortion & Term & \\
\hline Interval from index pregnancy, months & $<4$ & $\mathbf{4}-6$ & $\mathbf{7 - 1 2}$ & $>12$ \\
\hline Pretreatment hCGmIU/mL & $<13$ & $>103-104$ & $>104-105$ & $>105$ \\
\hline Largest tumor size including uterus, cm & - & $\mathbf{3}-\mathbf{4}$ & $\geq \mathbf{5}$ & - \\
\hline Site of metastases including uterus & lung & $\begin{array}{l}\text { Spleen, } \\
\text { kidney }\end{array}$ & $\begin{array}{l}\text { Gastrointesti } \\
\text { nal tract }\end{array}$ & Brain, liver \\
\hline Number of metastases identified & - & $\mathbf{1 - 4}$ & $\mathbf{5 - 8}$ & $>\mathbf{8}$ \\
\hline Previous failed chemotherapy & - & - & Single drug & $\begin{array}{l}\text { Two or more } \\
\text { drugs }\end{array}$ \\
\hline
\end{tabular}

Table 2. FIGO/WHO scoring system based on prognostic factors

Notes: To stage and allot a risk factor score, a patient's diagnosis is allocated to a Stage as represented by a Roman numeral I, II, III, or IV. This is then separated by a colon from the sum of all the actual risk factor scores expressed in Arabic numerals e.g. Stage II:4, Stage IV:9. This Stage and score will be allotted for each patient.

5.3.1- Low-risk gestational trophoblastic neoplasia :

Patients with low-risk GTN should be treated with one of the single-agent methotrexate or actinomycin D protocols listed in 1. The Cochrane Review in 2012, including 513 patients in five randomized controlled trials, showed that actinomycin $\mathrm{D}$ (Act-D) appeared to be superior to methotrexate (MTX) (risk ratio [RR] 0.64; 95\% confidence interval, [CI] 0.54-0.76) [26]. Methotrexate was associated with significantly more treatment failure than actinomycin D (RR 3.81; 95\% CI, 1.64-8.86). A further trial is ongoing, comparing not only efficacy, but toxicity and quality of life of pulsed actinomycin D and multiday methotrexate regimens [27].

- MTX-FA 8- day regimen (50 mg MTX intramuscularly on days 1,3,5,7 with folinic acid $15 \mathrm{mg}$ orally $24 \mathrm{~h}$ after MTX on days $2,4,6,8)$; repeat every 2 weeks.

• MTX $0.4 \mathrm{mg} / \mathrm{kg}$ (max. $25 \mathrm{mg}$ ) intravenously or intramuscularly for 5 days every 2 weeks.

- Actinomycin D pulse $1.25 \mathrm{mg} / \mathrm{m} 2$ intravenously every 2 weeks.

- Actinomycin D $0.5 \mathrm{mg}$ intravenously for 5 days every 2 weeks

- Others: MTX 30-50 mg/m2 intramuscularly weekly, MTX $300 \mathrm{mg} / \mathrm{m2}$ infusion every 2 weeks, 5-

fluorouracil, etoposide. 
Box 3 : Single-agent chemotherapy regimens for low-risk gestational trophoblastic neoplasia:

a Abbreviations: MTX-FA, methotrexate-folinic acid.

Chemotherapy should be changed to the alternative single agent if there has been a good response to the first agent but the hCG level plateaus above normal during treatment or if toxicity precludes an adequate dose or frequency of treatment. If there is an inadequate response to the initial single agent, a significant elevation in hCG level, development of metastasis, or resistance to sequential single-agent chemotherapy, multi-agent chemotherapy as for high-risk disease should be initiated [2]. Studies in the UK showed that if the hCG level is less than $100 \mathrm{IU} / \mathrm{L}$ or $300 \mathrm{IU} / \mathrm{L}$, change to single-agent Act-D gives a good response [2], [28], [29]; otherwise, multiple agents need to be used.

After the hCG level has returned to normal, consolidation with 2-3 more cycles of chemotherapy will decrease the chance of recurrence. The overall complete remission rate is close to $100 \%$ [2],[30].

\subsection{2- High-risk gestational trophoblastic neoplasia :}

Multiple agent chemotherapy regimens are used to treat high-risk GTN. The most commonly used is EMA-CO (etoposide, methotrexate, actinomycin D, cyclophosphamide, vincristine) (Table 3), although the Cochrane Database review [31] failed to conclude what combination was best. The complete remission rate was approximately $85 \%$ and the five-year overall survival rate was $75 \%-90 \%$. However, patients with liver and/or brain metastasis have poorer outcomes [32]-[34].

\begin{tabular}{|c|c|}
\hline $\begin{array}{l}\text { Regimens } \\
\text { Regimen } 1 \\
\text { Day } 1 \\
\text { Etoposide } \\
\text { Actinomycin-D } \\
\text { Methotrexate }\end{array}$ & $\begin{array}{l}100 \mathrm{mg} / \mathrm{m} 2 \text { intravenous infusion over } 30 \mathrm{minutes} \\
0.5 \mathrm{mg} \text { intravenous bolus } \\
100 \mathrm{mg} / \mathrm{m} 2 \text { intravenous bolus } ? ? 200 \mathrm{mg} / \mathrm{m} 2 \text { intravenous infusion over } \\
12 \mathrm{hours}\end{array}$ \\
\hline $\begin{array}{l}\text { Day } 2 \\
\text { Etoposide } \\
\text { Actinomycin-D } \\
\text { Folinic acid rescue }\end{array}$ & $\begin{array}{l}100 \mathrm{mg} / \mathrm{m} 2 \text { intravenous infusion over } 30 \text { minutes } \\
5 \mathrm{mg} \text { intravenous bolus } \\
15 \mathrm{mg} \text { intramuscularly or orally every } 12 \text { hours for four doses (starting } \\
24 \text { hours after beginning the methotrexate infusion) }\end{array}$ \\
\hline $\begin{array}{l}\text { Regimen } 2 \\
\text { Day } 8 \\
\text { Vincristine } \\
\text { Cyclophosphamide }\end{array}$ & $\begin{array}{l}1 \mathrm{mg} / \mathrm{m} 2 \text { intravenous bolus (maximum } 2 \mathrm{mg} \text { ) } \\
600 \mathrm{mg} / \mathrm{m} 2 \text { intravenous infusion over } 30 \text { minutes }\end{array}$ \\
\hline
\end{tabular}

Table 3. EMA-CO (etoposide, methotrexate, actinomycin D, cyclophosphamide, vincristine) chemotherapy

5.3.3- Ultra high-risk gestational trophoblastic neoplasia and salvage therapy:

Among the high-risk group as defined by the FIGO staging and classification, a subgroup with a score greater than or equal to 12 as well as patients with liver, brain, or extensive metastases did poorly when treated with first-line multiple agent chemotherapy[35].

For those with massive disease, starting with standard chemotherapy may cause severe marrow suppression leading to bleeding, septicemia, and even multiple organ failure. This may be avoided by starting with a lower dose and a less intensive 
regimen, such as etoposide $100 \mathrm{mg} / \mathrm{m} 2$ and cisplatin $20 \mathrm{mg} / \mathrm{m} 2$ on days 1 and 2 , repeated weekly for 1-3 weeks, before starting the usual chemotherapy regimen [36]. For those patients with liver or brain metastases or a very high-risk score, EP (etoposide and platinum)/EMA or another more intensive chemotherapy regimen (Table 4), rather than EMA, may yield a better response and outcome. Such regimens can also be used in treating relapse or progressive disease while on first-line chemotherapy. For such high-risk patients, a longer consolidation with four cycles of chemotherapy should be considered.

\begin{tabular}{|l|}
\hline - EP-EMA (etoposide, cisplatin, etoposide, methotrexate and actinomycin-D) \\
\hline - TP/TE (paclitaxel, cisplatin/paclitaxel, etoposide) \\
\hline - MBE (methotrexate, bleomycin and etoposide) \\
\hline - VIP or ICE (etoposide, ifosfamide, and cisplatin or carboplatin) \\
\hline - BEP (bleomycin, etoposide and cisplatin) \\
\hline - FA (5-fluorouracil, actinomycin-D) \\
\hline - FAEV (floxuridine, actinomycin-D, etoposide and vincristine) \\
\hline - High-dose chemotherapy with autologous bone marrow or stem cell transplant \\
\hline
\end{tabular}

Table 4. Salvage chemotherapy

In patients with brain metastases, an increase in the methotrexate infusion to 1 $\mathrm{g} / \mathrm{m} 2$ will help the drug cross the blood brain barrier and intrathecal methotrexate 12.5 $\mathrm{mg}$ can be given at the time of $\mathrm{CO}$ when EMA-CO is used. Some centers may give whole brain radiotherapy $3000 \mathrm{cGy}$ in 200 cGy daily fractions concurrent with chemotherapy or use stereotactic radiation to treat brain metastases.

5.4- Role of surgery :

Surgery may have an important role in the management of GTN. Hysterectomy can be considered in uncontrolled uterine bleeding, although it can often be avoided with the use of uterine artery embolization. Laparotomy may be needed to stop bleeding in organs such as the liver, gastrointestinal tract, kidneys, and spleen. Neurosurgery is needed if there is bleeding into the brain or increased intracranial pressure. In patients with an isolated drug-resistant tumor, removal of isolated cranial or pulmonary nodules or hysterectomy can improve survival.

5.5- Role of radiotherapy:

Radiotherapy has a limited role in GTN, except in treatment of brain metastasis, although its efficacy compared with intrathecal methotrexate is controversial [33], [37].

5.6- PSTT/ETT :

Both PSTT and ETT are less chemosensitive than choriocarcinoma. Hysterectomy is the primary mode of treatment in most cases. However, if fertility preservation is desired, especially in a localized lesion, conservative management such as uterine curettage, hysteroscopic resection, and chemotherapy may be considered. Fertility preservation is not suitable in diffuse lesions. EP-EMA is the most commonly used chemotherapy. Interval from antecedent pregnancy of more than 48 months seems to be the most significant adverse prognostic factor.

5.7- Follow-up :

After treatment of GTN, frequent monitoring of hCG for at least 12 months with reliable contraception is essential for surveillance of relapse.

Future fertility, pregnancy, and offspring are not affected, although psychosocial and sexual counseling may be needed for some patients. 


\section{References}

1. Hancock B.W., Nazir K., Everard J.E. Persistent gestational trophoblastic neoplasia after partial hydatidiform mole incidence and outcome. J Reprod Med. 51 (10): 2006; 764-766

2. Seckl M.J., Sebire N.J., Berkowitz R.S. Gestational trophoblastic disease. Lancet. 376 (9742): 2010; 717-729

3. Lurain J.R. Gestational trophoblastic disease I: epidemiology, pathology, clinical presentation and diagnosis of gestational trophoblastic disease, and management of hydatidiform mole. Am J Obstet Gynecol. 203 (6): 2010; 531539

4. Martin B.H., Kim J.H. Changes in gestational trophoblastic tumors over four decades. A Korean experience. J Reprod Med. 43 (1): 1998; 60-68

5. Steigrad S.J. Epidemiology of gestational trophoblastic diseases. Best Pract Res ClinObstetGynaecol. 17 (6): 2003; 837-847

6. Loukovaara M., Pukkala E., Lehtovirta P., Leminen A. Epidemiology of hydatidiform mole in

Finland, 1975 to 2001. Eur J GynaecolOncol. 26 (2): 2005; 207-208

7. Lybol C., Thomas C.M., Bulten J., et al. Increase in the incidence of gestational trophoblastic disease in The Netherlands. GynecolOncol. 121 (2): 2011; 334-338

8. Clement P.B., Young R.H., Trophoblastic lesions, miscellaneous primary uterine neoplasms, hematopoietic neoplasms, and metastatic neoplasms to the uterus. Clement P.B., Young R.H. Atlas of Gynecologic Surgical Pathology. 3rd ed. 2014; Saunders, Elsevier Inc: Oxford; 284-310

9. Fisher R.A., Hodges M.D., Rees H.C., Sebire N.J., Seckl M.J., Newlands E.S., et al. The maternally transcribed gene p57(KIP2) (CDNK1C) is abnormally expressed in both androgenetic and biparental complete hydatidiform moles. Hum Mol Genet. 11 (26): 2002; 3267-3272

10.Shen D.H., Khoo U.S., Ngan H.Y., Ng T.Y., Chau M.T., Xue W.C., et al.
Coexisting epithelioid trophoblastic tumor and choriocarcinoma of the uterus following a chemoresistanthydatidiform mole. Arch Pathol Lab Med. 127 (7): 2003; e291-e293

11.Chen B.J., Cheng C.J., Chen W.Y. Transformation of a post-cesarean section placental site nodule into a coexisting epithelioid trophoblastic tumor and placental site trophoblastic tumor: a case report. DiagnPathol. 8: 2013; 85

12.Luk W.Y., Friedlander M. A fibroid or cancer? A rare case of mixed choriocarcinoma and epithelioid trophoblastic tumour. Case Rep Obstet Gynecol. 2013: 2013; 492754

13. Kaur B., Short D., Fisher R.A., Savage P.M., Seckl M.J., Sebire N.J. Atypical placental site nodule (APSN) and association with malignant gestational trophoblastic disease; a clinicopathologic study of 21 cases. Int J GynecolPathol. 34 (2): 2015; $152-$ 158

14.Ngan H.Y., Bender H., Benedet J.L., Jones H., Montruccoli G.C., Pecorelli S., et al. Gestational trophoblastic neoplasia, FIGO 2000 staging and classification. Int J Gynecol Obstet. 83 (Suppl. 1): 2003; 175-177

15. Cole L.A. HyperglycosylatedhCG, a review. Placenta. 31 (8): 2010; 653664

16.Ngan H.Y., Kohorn E.I., Cole L.A., Kurman R.J., Kim S.J., Lurain J.R., et al. Trophoblastic disease. Int J Gynecol Obstet. 119 (Suppl. 2): 2012; S130S136

17.Sebire N.J., Foskett M., Short D., Savage P., Stewart W., Thomson M., et al. Shortened duration of human chorionic gonadotrophin surveillance following complete or partial hydatidiform mole: evidence for revised protocol of a UK regional trophoblastic disease unit. BJOG. 114 (6): 2007; 760-762

18. Costa H.L., Doyle P. Influence of oral contraceptives in the development of post-molar trophoblastic neoplasia-a 
systematic review. GynecolOncol. 100 (3): 2006; 579-585

19.Matsui H., Iitsuka Y., Suzuka K., Seki K., Sekiya S. Subsequent pregnancy outcome in patients with spontaneous resolution of HCG after evacuation of hydatidiform mole: comparison between complete and partial mole. Hum Reprod. 16 (6): 2001; 1274-1277

20.Sebire N.J., Fisher R.A., Foskett M., Rees H., Seckl M.J., Newlands E.S. Risk of recurrent hydatidiform mole and subsequent pregnancy outcome following complete or partial hydatidiform molar pregnancy. BJOG. 110 (1): 2003; 22-26

21.Tse K.Y., Ngan H.Y. Gestational trophoblastic disease. Best Pract Res ClinObstetGynaecol. 26 (3): 2012; 357-370

22.Fisher R.A., Hodges M.D., Newlands E.S. Familial recurrent hydatidiform mole: a review. J Reprod Med. 49 (8): 2004; 595-601

23.Williams D., Hodgetts V., Gupta J. Recurrent hydatidiform moles. Eur $\mathrm{J}$ ObstetGynecolReprod Biol. 150 (1): 2010; 3-7

24.Ulker V., Gurkan H., Tozkir H., Karaman V., Ozgur H., Numanoglu C., et al. Novel NLRP7 mutations in familial recurrent hydatidiform mole: are NLRP7 mutations a risk for recurrent reproductive wastage?.Eur $\mathrm{J}$ ObstetGynecolReprod Biol. 170 (1): 2013; 188-192

25.Sebire N.J., Foskett M., Paradinas F.J., Fisher R.A., Francis R.J., Short D., et al. Outcome of twin pregnancies with complete hydatidiform mole and healthy co-twin. Lancet. 359 (9324): 2002; 2165-2166

26.Alazzam M., Tidy J., Hancock B.W., Osborne R., Lawrie T.A. First-line chemotherapy in low-risk gestational trophoblastic neoplasia. Cochrane Database Syst Rev. 7: 2012; CD007102

27. National Cancer Institute website, http://www.cancer.gov/clinicaltrials/sea $\mathrm{rch} /$ view? cdrid=725211\&version=Heal thProfessional \& protocolsearchid $=8014$ 242

28. McNeish I.A., Strickland S., Holden L., Rustin G.J., Foskett M., Seckl M.J., et al. Low-risk persistent gestational trophoblastic disease: outcome after initial treatment with low-dose methotrexate and folinic acid from 1992 to 2000. J ClinOncol. 20 (7): $2002 ; 1838-1844$

29.McGrath S., Short D., Harvey R., Schmid P., Savage P.M., Seckl M.J. The management and outcome of women with post-hydatidiform mole 'low-risk' gestational trophoblastic neoplasia, but hCG levels in excess of 100000 IU 1(- 1). Br J Cancer. 102 (5): 2010; 810-814

30.Lurain J.R. Gestational trophoblastic disease II: classification and management of gestational trophoblastic neoplasia. Am J Obstet Gynecol. 204 (1): 2011; 11-18

31.Deng L., Zhang J., Wu T., Lawrie T.A. Combination chemotherapy for primary treatment of high-risk gestational trophoblastic tumour. Cochrane Database Syst Rev. 1: 2013; CD005196

32. Ahamed E., Short D., North B., et al. Survival of women with gestational trophoblastic neoplasia and liver metastases: is it improving?. J Reprod Med. 57 (5-6): 2012; 262-269

33. Neubauer N.L., Latif N., Kalakota K., Marymont M., Small W. Jr, Schink J.C., et al. Brain metastasis in gestational trophoblastic neoplasia: an update. J Reprod Med. 57 (7-8): 2012; 288-292

34.Newlands E.S., Holden L., Seckl M.J., McNeish I., Strickland S., Rustin G.J. Management of brain metastases in patients with high-risk gestational trophoblastic tumors. J Reprod Med. 47 (6): 2002; 465-471

35. Crawford R.A., Newlands E., Rustin G.J., Holden L., A'Hern R., Bagshawe K.D. Gestational trophoblastic disease with liver metastases: the Charing Cross experience. Br J ObstetGynaecol. 104 (1): 1997; 105-109

36. Alifrangis C., Agarwal R., Short D., Fisher R.A., Sebire N.J., Harvey R., et al. EMA/CO for high-risk gestational trophoblastic neoplasia: good outcomes with induction low-dose etoposide-cisplatin and genetic 
SOHAG MEDICAL JOURNAL Gestational trophoblastic disease updated management

analysis. J ClinOncol. 31 (2): 2013; 280-286

37.Piura E., Piura B. Brain metastases from gestational trophoblastic neoplasia: review of pertinent literature. Eur J GynaecolOncol. 35 (4): 2014; 359-367 